\title{
Long-term Trends of Volatile Organic Compounds over the Texas, USA in the Past Two Decades
}

\author{
Ruizhe Liu* \\ University of Maryland, United States
}

\begin{abstract}
Volatile organic compounds (VOCs) are organic compounds in the air that have low vapor pressure. VOCs can be emitted from a variety of sources including biogenic, anthropogenic and pyrogenic processes. VOCs are precursors of aerosols and tropospheric O3, which harm human health. However, the potential of VOCs forming secondary air pollutants varies by species. Here, we analyze the long-term trends of source, concentration and reactivity of six classes of VOCs from 1995 to 2018 over Texas, USA. VOCs emission from petroleum and related companies in Texas kept increasing these years. Among the VOCs tracers of oil and gas companies, the concentration of ethane kept increasing until 2015. Despite the increase of oil and gas related VOCs, the concentration of total VOCs and reactivity-weighted VOCs have decreased in the past two decades. We further investigate the seasonality of VOC reactivities, which depend on both temperature and VOC concentration. We find that VOC reactivity generally is highest in fall and lowest in spring, and such seasonality does not change over the two decades.
\end{abstract}

\section{Introduction}

Generally, volatile organic compounds (VOCs) refer to those that can evaporate under normal temperature and pressure, or indoor atmospheric conditions[1]. The common species include acetone, benzene, ethane, toluene, and so on[1]. In nature, VOCs contribute to communication between plants and animals, doing good to nature. As for humans, however, even breathing low levels of VOCs may lead to increase people's risk of health problems such as eye, nose and throat irritation, headaches, nausea, and even cancer. [1,2]. Other than water-soluble chemicals, volatile chemicals can be inhaled and absorbed through the skin because of vaporization, displaying a higher possibility of health effects[3]. [2] Inhalation of trimethyl benzenes, xy-lenes, benzene, and alkanes can cause unconsciousness at higher exposures. [4]. In atmospheric chemistry, VOCs cause formation of surface ozone a major air pollutant harmful to human health. lung function can be reduced in a high level of ozone. [5][6] Besides, ozone is a greenhouse gas. VOCs produce tropospheric ozone through photochemical reactions with the reactive hydroxyl $\operatorname{radical}(\mathrm{OH})$. The product can be combined with anthropogenic NOx to produce ozone. In urban summer, hourly average concentrations of tropospheric ozone can be about $150 \mathrm{ppbv}$ after solar noon.[7]

Vehicle and oil and gas production are recognized as two important sources of VOC emission in 20th century. Over the U.S., vehicular emission has been reduced by $59 \%$ since the control of on-road vehicle emission was introduced.[8] VOC emission in the United States decreased significantly over the past two decades.
Approximately 7960 kton was reduced from 1990 to 2017. (Figure 1) For different sources of the emission, highway vehicles contributed much less in 2017. In addition, most sources lead to less emission now such as violent utilization and off-highway vehicles. However, the amount of emission from petroleum and related industries was becoming much larger in these years in the United States. The main petroleum products are divide into three primary categories: fuels(i.e. motor gasoline, fuel oil), finished non-fuel products(i.e. solvents), and chemical industry feedstocks(i.e. ethane, propane).[9] Air sample was collected in the Marcellus Shale southwestern Pennsylvania, results indicated that the majority of $\mathrm{C} 2-\mathrm{C} 8$ alkanes were originated from unconventional natural gas.[10] Considerable emission of VOCs from petroleum and related industries also increases the production of ozone. Gilman et al. [2013] reported that approximately half $(55 \pm 18 \%)$ of VOCs initiated the ozone production cycle is originated from oil and gas production.[11] At the Boulder Atmospheric Observatory, C2-C6 alkanes dominated the reaction of VOCs and hydroxyl radical $(\mathrm{OH})$ because of their large abundances.

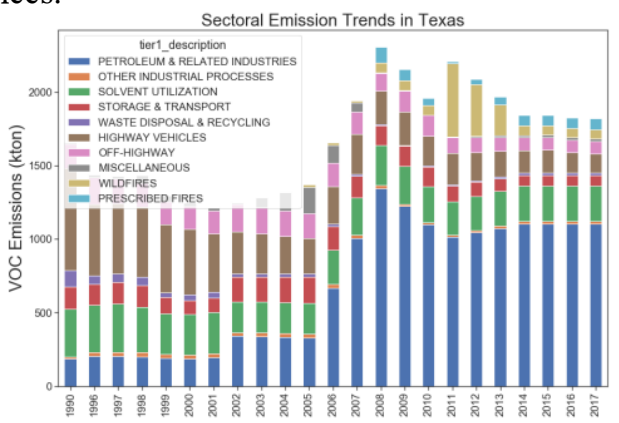

(a)

\footnotetext{
* Corresponding author: evanlrz@163.com
} 


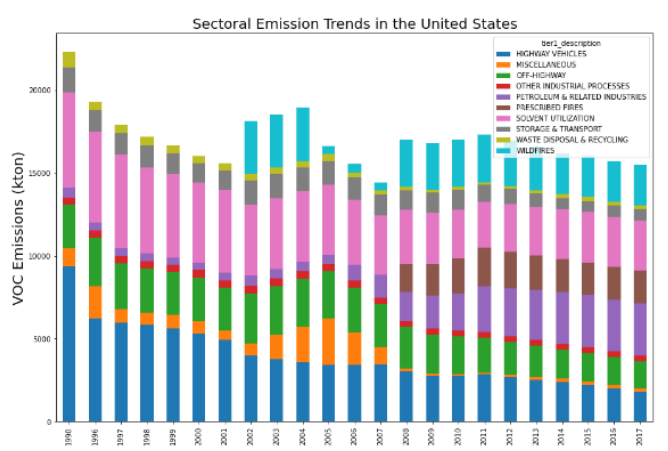

(b)

Fig. 1. (a) Sectoral Emission Trends of VOCs in Texas;

(b) Sectoral Emission Trends of VOCs in the United

In USA, the emission of VOCs in the United States has declined from 22042 kton in 1995 to 16202 kton in 2017(Figure 1) while the emission trends in Texas changed anomalously, 1766kton in 1990 to $1865 \mathrm{kton}$ in 2017(Figure 1). A series of changes in the long term trend of VOC emission in Texas caused our interest. The daily concentration of VOCs in each site was measured at Photochemical Assessment Monitoring Stations (PAMS). We investigate the long-term trends of VOC emissions and concentration from major sectors: petroleum and related industries, other industrial processes, solvent utilization, storage and transport, waste disposal and recycling, highway vehicles, offhighway vehicles, miscellaneous, wildfires, and prescribed fires. Furthermore, we explore how the concentration of various VOCs from major sectors have changed in the past two decades.

At La Porte in Texas, the abundance of various kinds of VOCs (i.e. ethene, propene, 1-butene, C2-C4 alkanes) are due to emissions from the petrochemical industry. C1-C3 aldehydes generally dominated air mass reactivity. Roadway vehicle emissions were generally dominated by most aromatics and long-chain alkanes.[12] Higher ozone production rates were measured in the region with a high concentration of VOCs. Berkowitz et al. indicated that VOC samples in Houston were raised when $\Delta \mathrm{O} 3 / \Delta \mathrm{t}>20 \mathrm{ppb}$ per $15 \mathrm{~min}$ and simulated ozone production can be $50 \mathrm{ppb}$ per hour when air pass through eastern Houston with rich emission of VOCs.[13] In Northeast Texas, photochemical modeling of emission in 2012 showed increases up to $5 \mathrm{ppb}$ in 8-hour ozone design values due to development in the Haynesville Shale.[14] Many studies indicate that the VOCs emissions show a clear seasonal cycle (VOCs trends in Dallas seasonally, VOCs trends in lower polar Troposphere seasonally), which motivates us to study how the trends of reactivities of VOCs with OH (VOCR) changed.

\section{Experiments}

\subsection{Emission inventory data}

The emission data are accessed from the National Emissions Inventory (NEI), which is an exhaustive estimate of VOC emissions from the emissions sources. Emissions from 1991 to 1995 are not available on a state tier level. 1996-2001 emissions were calculated for given NEI years. Emissions in 1996 are given and results in 1998 were estimated through 1996 NEI as a base year. [1] Similar approaches were used to get 2000 and 2001 based on 1999 NEI. 2002, 2005, 2008, 2011, and 2014 were given years so the rest years were estimated using inter interpolation.

The emission data are accessed from the National Emissions Inventory (NEI), which is an exhaustive estimate of VOC emissions from the emissions sources. Emissions from 1991 to 1995 are not available on a state tier level. 1996-2001 emissions were calculated through methodologies for given NEI years. Emissions in 1996 are given and results in 1998 were estimated through 1996 NEI as a base year. Similar approaches were used to get 2000 and 2001 based on 1999 NEI. 2002, 2005, 2008, 2011, and 2014 were estimated directly from the survey, and the rest years were estimated using interpolation.

\subsection{PAMS observations}

The VOCs daily concentration data are acquired from Photochemical Assessment Monitoring Stations (PAMS), which are part of the State Implementation Plan (SIP) monitoring networks for the enhanced monitoring of ozone, NOx, and VOCs. Five sites for a large area have been consistent in the minimum network to make data sufficient to satisfy plenty of essential monitoring objectives. The five sites contained: upwind and background characterization site, maximum ozone precursor emissions impact site, maximum ozone concentration site, and extreme downwind monitoring site. A total of 56 target hydrocarbons are measured every one or three hours during the ozone season. Formaldehyde, acetaldehyde, and acetone are collected in maximum ozone precursor emissions impact site on a 3-hour basis.

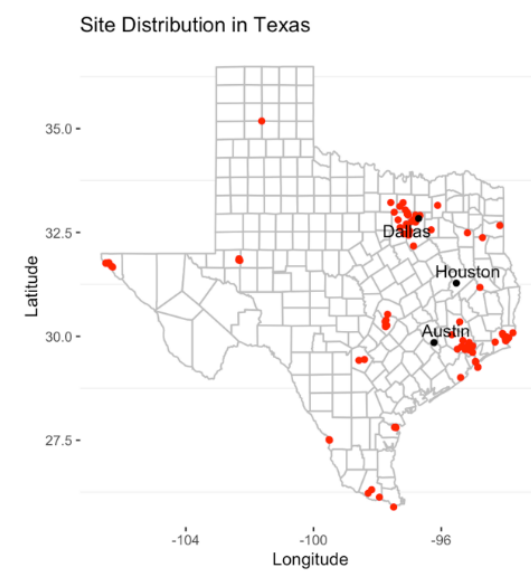

Fig. 2. Site distribution(red points) in Texas. 
In PAMS data, there were 109 sites including 46 cities in the Texas States. (Fig. 2) The cities with most data include Houston, El Paso, Dallas, Deer Park, Odessa, and Corpus Christi. The data of each site are not complete from 1995 to 2018, such as Cleveland Ave at Clark Dr (1995 to 2014), 3810 Huisache Street (1997 to 2014). We filtered all the data higher than 3 times of standard deviation plus the median, which are considered as outliers.

\subsection{Calculation of VOC reactivities}

For aldehydes and ketones, aromatics and Temperatureindependent Alkane, their values of $\mathrm{kT}$ are constant, independent of temperature. Alkene, aromatics, C1-C2 aldehydes and temperature-dependent alkane are fit as exponential functions of temperature. The equations below are used to get each VOCR value. Daily temperatures in each place are from EPA documents.

\section{Results}

\subsection{VOC emissions}

Emissions from Texas increased sharply from 1434kton in 2005 to $2361 \mathrm{kton}$ in 2008 (Fig. 1). After reaching the maximum in 2008, the trends of emissions still experienced rising and falling from 2008 to 2014, then kept about 1800kton after 2014. From Fig. 1, we can see that most emission sectors are highway and off-highway vehicles, solvent utilization, and petroleum and related industries. In the beginning, highway vehicle emission was larger than any other sector in 1990 . However, with the increasing trend from petroleum industries and decreasing trend from vehicles, petroleum, and related industries became the most dominant emission source.

In the beginning, the highway vehicles emission were larger than any other sectors in 1990s. However, with the increasing trend from petroleum industries and decreasing trend from vehicles, petroleum, and related industries became the most emission source in the latest years. The solvent utilization emissions changed from $326 \mathrm{kton}$ in 1990 to $242 \mathrm{kton}$ in 2017, leading to a rising trend from 2005 to 2008 then dropping. On the contrary, the petroleum and related industries emission has increased from 183kton in 1990 increased sharply to $1104 \mathrm{kton}$. The number of gas and gas condense wells increased in Texas from 1990(50867 numbers) to 2014(14292 numbers), particularly more than 40000 numbers rising from 2010(95014 numbers) to 2011(139368 numbers). For Texas natural gas industrial consumption, there was a general decline showing from 1997(2049 trillion cubic feet) to 2009(1198 trillion cubic feet) following by a slowly growing till 2018(1821 trillion cubic feet).

\subsection{VOCs concentration}

\subsubsection{Seasonality}

There is a clear seasonal trend (Fig. 3): VOC concentrations peak in January, while the smallest concentration happened in June. These are linked to the source and chemical lifetime of VOCs. The lifetime of VOCs is shorter in summer because some kinds of VOCs are more active in a higher temperature, which means these VOCs can be easily converted to other intermediate species. This kind of VOCs reaction is temperature-dependent while there is also VOCs reaction which is temperature-independent, with no change with temperature rise or down. Hence, more VOCs are reacted to produce HOx in the summer, leading to less VOCs concentration in summer in Texas. In addition, the light intensity can also affect the VOCs activity as ozone is formed in the reaction of oxygen and $\mathrm{O}(3 \mathrm{P})$ atom, and the $\mathrm{O}(3 \mathrm{P})$ atom is from the decomposition of $\mathrm{NO} 2$ absorbing photons. In winter, the photolysis is not strong because of less light duration and intensity, making decreased photochemistry in the process of ozone formation. In terms of anthropogenic point, the natural gas industrial consumption always peaks in winter, leading to the peak of the VOCs concentrations. The natural gas industrial consumption, one of the main sources of VOCs, shows a seasonal trend, most consumption between November and January and less consumption in June, September, and October. Although the consumption in summer is not the least, more active reaction rate because of highlight intensity and the temperature seems the main reason making the least emission appear in June. Overall, the seasonality of VOC concentrations reflects the combined effects of meteorology and emissions.

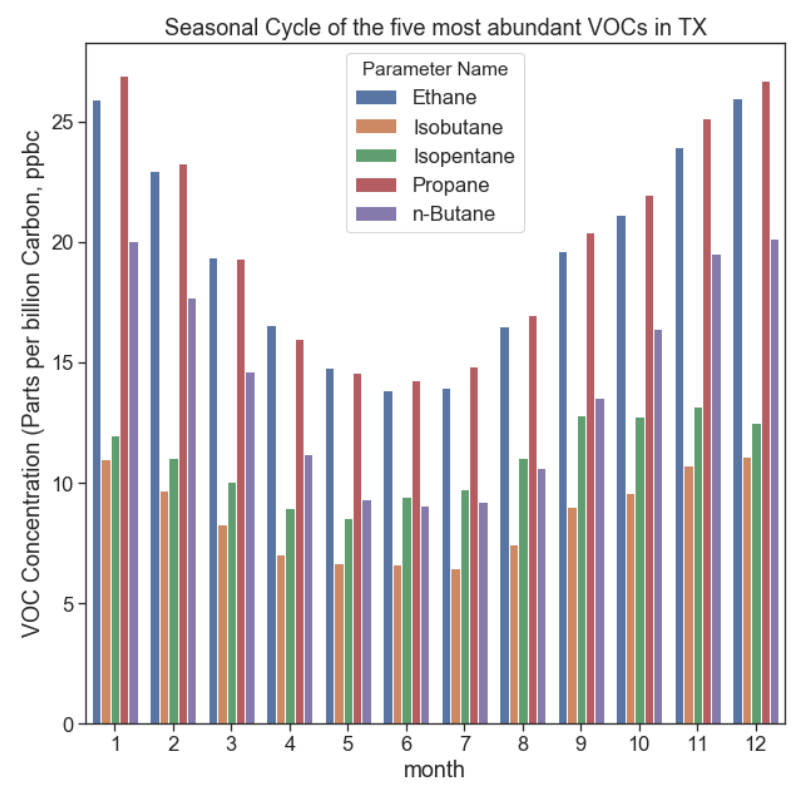

Fig.3. Seasonal cycle of the five most abundant VOCs in Texas

\subsubsection{Long-term trends}

From Fig. 4, we can see that the trend of VOCs emission from solvent utilization is not constant, full of up and down. From the development tendency of the VOCs 
which are tracers of solvent (Fig. 1), we can find that most of them keep decreasing and toluene decreased most in around 2000.

To track the sources VOCs from solvent utilization, we conduct such analysis at each site in Texas. Many refineries were near Cleveland Ave at Clark Dr. There were many refineries in Jefferson and many solvent utilizations around Houston, so 3355 Grandview Ave and 32nd St has high VOCs concentration, and there was a solvent near the 3810 Huisache Street and 1713 2nd Street, so these two streets had higher VOCs. Isobutane and isopentane are the main VOCs from solvents, most abundant species on the figure. However, the concentrations of VOCs vary among spatially among sites, for the following reasons. First, isobutane is also the tracer of consumer products and both of them are tracers of gasoline, so more vehicles in Houston cause more emissions in 3355 Grandview avenue. Second, there may be more consumer product companies around. Third, from the trends of these figures, it seems that the solvent utilizations near Houston have been controlled, showing decreasing trends and the solvent near the last 2 streets is becoming more and more important, increasing since 2010 in the last 2 figures.

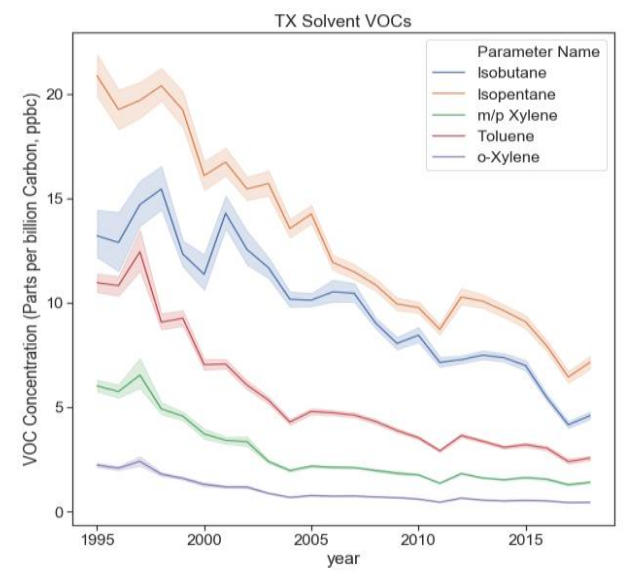

(a)

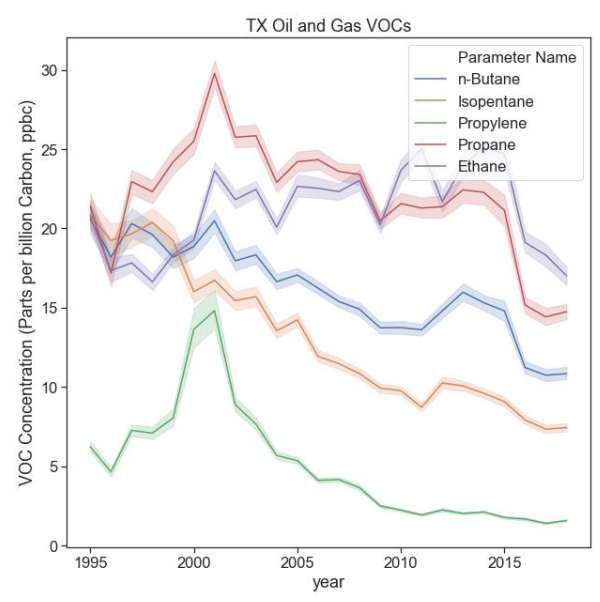

(b)

Fig. 1. (a) Trends of VOCs from solvent in Texas; (b)Trends of VOCs from oil and gas in Texas.
Among the VOC species shown in Fig. 4, ethane, nbutane, isopentane, propane and propylene were tracers of oil and gas. Their trends show changes of consumption of oil and gas these years. (Fig. 4) Nbutane and isopentane were the main tracers of gasoline and the decline of the abundance showed decreasing consumption of gasoline. The two main sources of propylene are from the steam cracking of liquid feedstocks and from off-gases produced in fluid catalytic cracking (FCC) units in refineries. The up in approximately 2000 and then downtrends in Fig. 4 mean that those technologies with a high concentration of propylene happening were popular in around 2000 then out of date generally. Ethane is a tracer of natural gas use and the source of propane is from nature oil gas use and oil and gas production. The concentrations of these two species are much greater than others may because more consumption of natural gas use in recent years and they are both non-reactive gases. Barrett and Monahans streets and $800 \mathrm{~S}$ San Marcial street are the places with the most concentration of VOCs from petroleum industries because there are oil and natural gas companies around there. The low concentration of VOCs from vehicle and solvent suggests that the main sources of the sites are from oil and natural gas use.

\subsection{VOCs reactivities}

\subsubsection{Long-term trends}

The concentration of VOCs affects reactivities. From 2005, the concentration of VOCs kept decreasing, making reactivities decrease consistently. The arithmetic mean and VOC reactivity from 1995 to 2004 was larger than the following periods, from 2005 to 2019(Fig. 5), leading reactivities of VOCs in these ten years significantly high. The arithmetic mean from 1995 to 1999 in September is 51 ppbc larger than the following 5 years, making the largest difference in the figure. Correspondingly, the largest difference in VOCR seasonal cycle was also between these two periods, 2.3 s-1. The great gap between 2000 to 2004 and 2005 to 2009 appears in January, all above 40 ppbc. In response, the VOCR in January from 2005 to 2009 decreasing 2.3 $\mathrm{s}-1$, reducing most in the seasonal cycle comparing to the last five years. The reductions in the latest three periods (2005 to 2009,2010 to 2014,2015 to 2019) decreased in both concentration and reactivities of VOCs.

\subsubsection{Seasonality}

VOCR is largely dependent on temperature. In Fig. 5, from January to April in the period (2000 to 2004), the concentration of VOCs was larger than the previous 5 years (1995 to 1999) while VOCR in this period (2000 to 2004) was lower. To further understand the effect of temperature on each type of VOCs, VOCs in this research were divided into 7 classes: aldehydes and ketones, alkene, aromatics, biogenic VOC, C1-C2 aldehydes, temperature-dependent alkane, and temperature-independent alkane. C1-C2 aldehydes and 
temperature-dependent alkane were most affected by temperature: with rising temperature, the value VOCR of C1-C2 aldehydes would be increase while that of temperature-dependent alkane would be lower (Fig. 6). This discovery illustrated VOCR of C1-C2 aldehydes was greater in the period from 1995 to 1999, given higher temperature and arithmetic mean of $\mathrm{C} 1-\mathrm{C} 2$ aldehydes in winter and spring. On the contrary, temperature-dependent alkane has an opposite response to temperature: higher VOCR at a lower temperature. Thus, greater arithmetic means of temperature-dependent alkane in the period (2000 to 2004) and the lower temperature could benefit the VOCR of this class.

To make further analysis of season trends of properties of VOCR, the trends of $\mathrm{kT}$, VOCR, temperature, and arithmetic mean of each class have been shown. (Fig. 5) There are three kinds of trends of VOCR in a seasonal cycle: the values of VOCR of C1$\mathrm{C} 2$ aldehydes and biogenic VOCs were greater in a warmer temperature, the VOCR of temperaturedependent alkane and alkene were greater in a cold environment and VOCR of other types would not change with temperature.

Reactivities in all the periods in the figure, except from 2000 to 2004, were at their peak in September and fell to the lowest in March or April. As mentioned, which are due to the combined effects of temperature and concentration. Although temperature reached a peak in July, the concentration of VOCs is at around the lowest points. In September, the concentration rose fast and the temperature was still remaining a high value, so the reactivities reach the peak. Comparing to the arithmetic mean in July in each period, the values in September increased $45.8 \%, 34.7 \%, 39.3 \%, 38.2 \%$ and $52.5 \%$ in 1995 to 1999,2000 to 2004,2005 to 2009 , 2015 to 2019, respectively. In contrast, the relative reduction of temperatures in September were $6.2 \%, 7.2 \%$, $5.6 \%, 5.33 \%$, and $6.7 \%$, much lower than the changes in concentration. Similarly, values of reactivities dropped to the lowest points because the concentration and temperature are both at a low level.
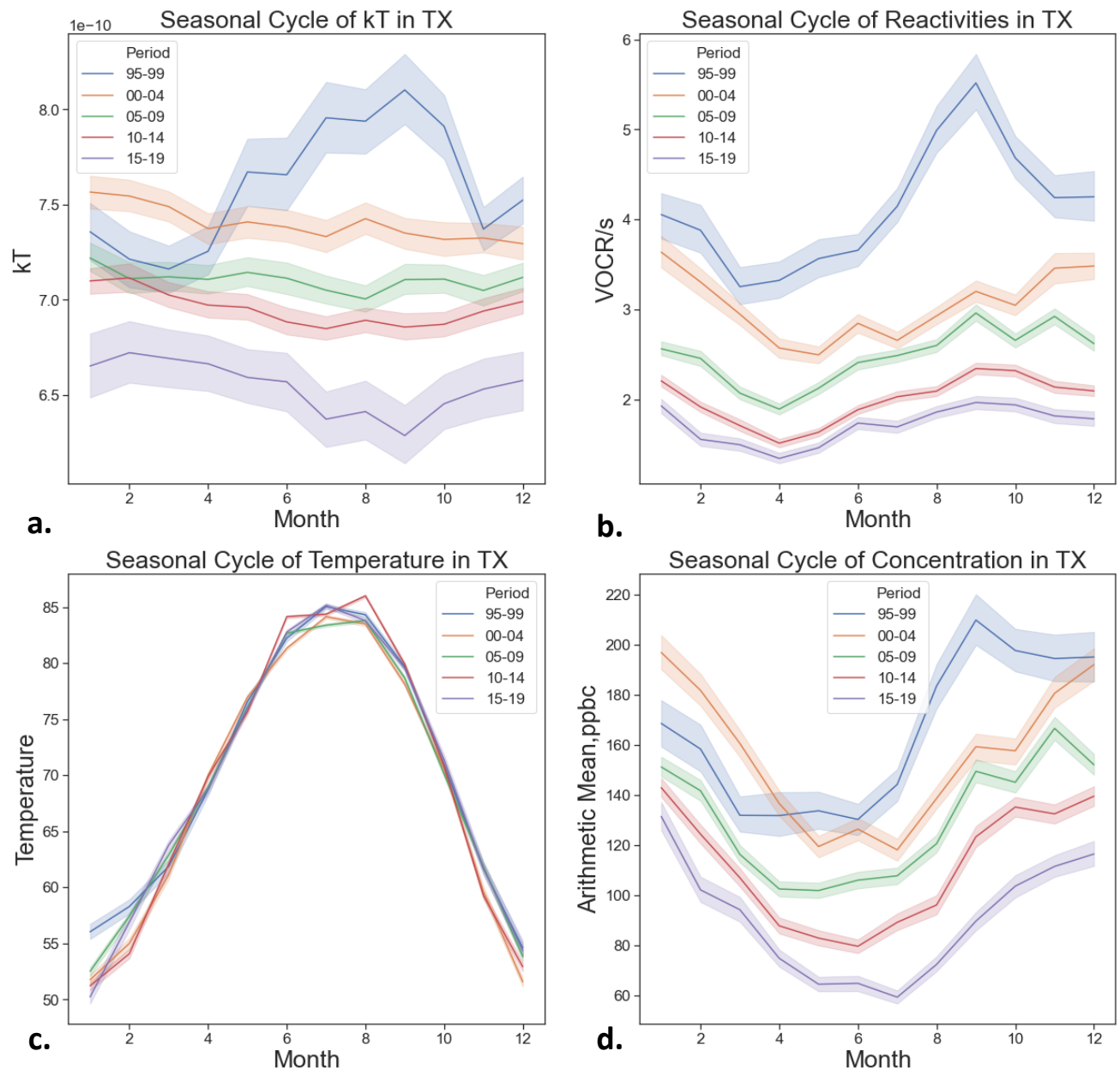

Fig. 5. Seasonal cycle of kT(a), reactivities(b), temperature(c) and concentration(d) in Texas(95-99 refers to period from 1995 to 1999; 00-04 refers to period from 2000 to 2004; 05-09 refers to period from 2005 to 2009; 10-14 refers to period from 2010 to 2014 ; 15-19 refers to period from 2015 to 2019 ). 

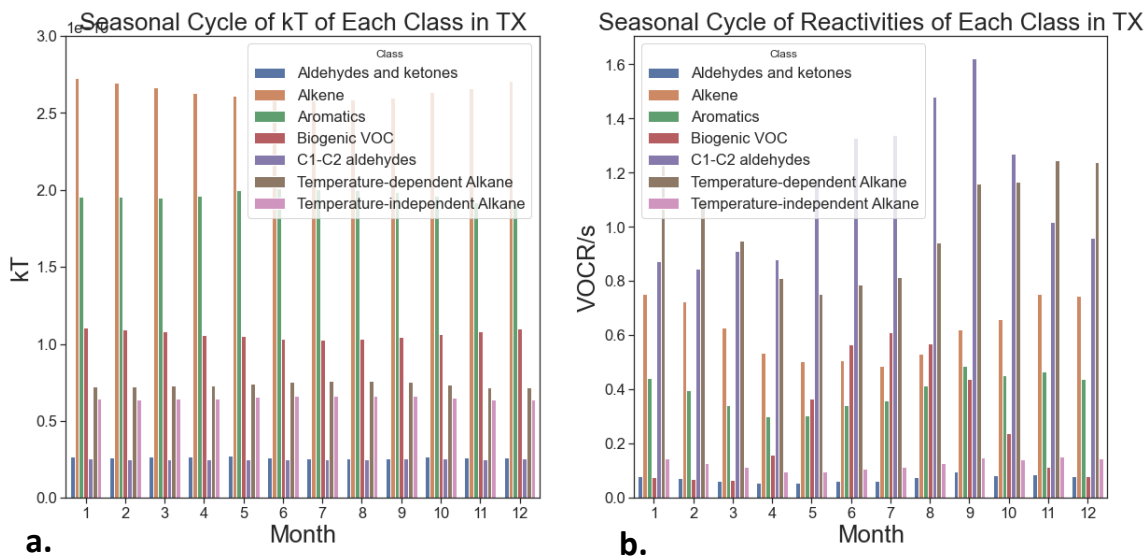

Seasonal Cycle of Temperature of Each Class in TX Seasonal Cycle of Concentration of Each Class in TX
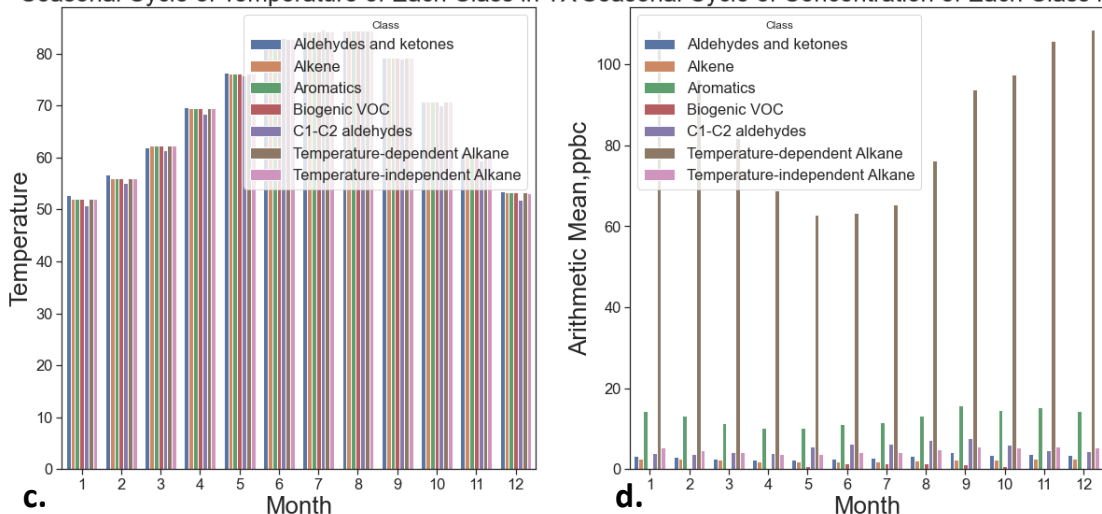

Fig. 6. Seasonal cycle of kT(a), reactivities(b), temperature(c), and concentration(d) of each class in Texas.

The trend in the periods from 2000 to 2004 was an exception, being at peak in winter and dropping to the lowest point in summer. We inferred that the unusual trend happened because of relatively lower temperature especially in summer in this period (Fig. 6). Cooler temperature in summer caused the VOCR of biogenic VOCs to be lower comparing with other periods. The VOCR values of biogenic VOCs (2000 to 2004) from June to October kept the lowest in all the periods (Table 1), making total VOCR in summer in this period not be high as other periods. Furthermore, VOCR of alkene in the period (2000-2004) was also higher, particularly in winter given a cold environment. From November to February, the reactivities are more than $1.00 \mathrm{~s}-1$ (Table 1 ), greatest value in all periods except former 5 years, 1995 to 1999. What's more, the weight of Alkene in all the classes in 00 to 04 was much larger $(20.9 \%)$ than 1995 to $1999(18.0 \%), 2005$ to $2009(17.5 \%), 2010$ to 2014(13.6\%) and 2015 to 2019(11.3\%), which means the alkene in 2000 to 2004 distributed more on the total VOCR trends. In the same way, the weight of biogenic VOCs in 2000 to $2004(6.0 \%)$ was much lower than in other periods except 1995 to 1999 . Hence, higher concentration of alkene leads to the VOCR values in winter was much higher while less biogenic VOCs have a lower weight on total VOCR and make the max value move to January.

\section{Conclusions}

We find distinct seasonal cycle of VOC concentration and VOC reactivity in Texas. VOC concentrations peak in winter, which is due to the consumption of the natural gas and longer lifetime of VOCs industries in winter. Besides, solvents and petroleum and related industries also contribute to the overall VOCs, which is evidence from large amount of Isobutane and isopentane (tracers of solvent related VOCs). Reactivities generally peak in September and fall to the lowest point in March or April. In September, the concentration rose fast and the temperature was still remaining a high value, so the reactivities reach the peak. Different classes of VOCs show variations in seasonal cycle: the values of VOCR of $\mathrm{C} 1-\mathrm{C} 2$ aldehydes and biogenic VOCs were greater in a warmer temperature, the VOCR of temperaturedependent alkane and alkene were greater in a cold environment and VOCR of other types would not change with temperature. The concentration of ethane has increased in the past two decades because of increasing consumption of oil and gas use, but the overall VOC concentration shows declining trends. The long-term decrease in VOC concentrations largely lead to decrease of overall VOC reactivities. Overall, we conclude that the emission control has led significant reduction of the hazardous VOC concentration, and also less potential to form secondary pollutants. 
Table 1. Seasonal VOCR of Each Class in Each Five Years

\begin{tabular}{|c|c|c|c|c|c|c|}
\hline \multirow[t]{2}{*}{ Period } & \multirow[t]{2}{*}{ Class } & \multicolumn{5}{|c|}{$\operatorname{VOCR}(/ \mathrm{s})$} \\
\hline & & JAN to MAR & APR to JUN & $\begin{array}{l}\text { JUL to } \\
\text { SEP }\end{array}$ & $\begin{array}{l}\text { OCT to } \\
\text { DEC }\end{array}$ & SUM \\
\hline \multirow[t]{8}{*}{1995 to 1999} & Aldehydes and ketones & 0.108 & 0.100 & 0.168 & 0.134 & 0.509 \\
\hline & Alkene & 1.262 & 0.968 & 1.066 & 1.313 & 4.608 \\
\hline & Aromatics & 0.787 & 0.744 & 1.168 & 0.908 & 3.607 \\
\hline & Biogenic VOC & 0.105 & 0.419 & 0.564 & 0.195 & 1.283 \\
\hline & $\mathrm{C} 1-\mathrm{C} 2$ aldehydes & 1.870 & 2.329 & 2.515 & 2.176 & 8.890 \\
\hline & Temperature-dependent Alkane & 1.237 & 1.036 & 1.446 & 1.539 & 5.258 \\
\hline & $\begin{array}{l}\text { Temperature-independent } \\
\text { Alkane }\end{array}$ & 0.196 & 0.170 & 0.255 & 0.211 & 0.832 \\
\hline & Sum & 5.564 & 5.766 & 7.182 & 6.476 & 24.99 \\
\hline \multirow[t]{8}{*}{2000 to 2004} & Aldehydes and ketones & 0.089 & 0.067 & 0.067 & 0.095 & 0.318 \\
\hline & Alkene & 1.081 & 0.761 & 0.738 & 1.047 & 3.627 \\
\hline & Aromatics & 0.520 & 0.418 & 0.454 & 0.526 & 1.919 \\
\hline & Biogenic VOC & 0.078 & 0.344 & 0.457 & 0.133 & 1.011 \\
\hline & C1-C2 aldehydes & 1.064 & 1.263 & 1.603 & 1.220 & 5.149 \\
\hline & Temperature-dependent Alkane & 1.348 & 0.909 & 1.016 & 1.360 & 4.634 \\
\hline & $\begin{array}{l}\text { Temperature-independent } \\
\text { Alkane }\end{array}$ & 0.143 & 0.112 & 0.116 & 0.145 & 0.515 \\
\hline & Sum & 4.324 & 3.873 & 4.451 & 4.526 & 17.17 \\
\hline \multirow[t]{8}{*}{2005 to 2009} & Aldehydes and ketones & 0.059 & 0.045 & 0.054 & 0.066 & 0.224 \\
\hline & Alkene & 0.685 & 0.520 & 0.534 & 0.695 & 2.433 \\
\hline & Aromatics & 0.368 & 0.278 & 0.358 & 0.446 & 1.451 \\
\hline & Biogenic VOC & 0.077 & 0.370 & 0.570 & 0.154 & 1.171 \\
\hline & C1-C2 aldehydes & 0.732 & 1.066 & 1.275 & 0.914 & 3.987 \\
\hline & Temperature-dependent Alkane & 1.045 & 0.806 & 0.995 & 1.223 & 4.070 \\
\hline & $\begin{array}{l}\text { Temperature-independent } \\
\text { Alkane }\end{array}$ & 0.130 & 0.103 & 0.133 & 0.153 & 0.519 \\
\hline & Sum & 3.096 & 3.189 & 3.918 & 3.652 & 13.86 \\
\hline \multirow[t]{8}{*}{2010 to 2014} & Aldehydes and ketones & 0.040 & 0.031 & 0.039 & 0.050 & 0.160 \\
\hline & Alkene & 0.453 & 0.318 & 0.337 & 0.454 & 1.562 \\
\hline & Aromatics & 0.280 & 0.201 & 0.244 & 0.312 & 1.038 \\
\hline & Biogenic VOC & 0.058 & 0.351 & 0.535 & 0.123 & 1.066 \\
\hline & C1-C2 aldehydes & 0.731 & 0.890 & 1.103 & 0.804 & 3.528 \\
\hline & Temperature-dependent Alkane & 0.996 & 0.678 & 0.862 & 1.119 & 3.655 \\
\hline & $\begin{array}{l}\text { Temperature-independent } \\
\text { Alkane }\end{array}$ & 0.115 & 0.084 & 0.111 & 0.135 & 0.444 \\
\hline & Sum & 2.672 & 2.553 & 3.231 & 2.997 & 11.45 \\
\hline \multirow[t]{8}{*}{2015 to 2019} & Aldehydes and ketones & 0.035 & 0.024 & 0.024 & 0.037 & 0.120 \\
\hline & Alkene & 0.331 & 0.231 & 0.239 & 0.345 & 1.145 \\
\hline & Aromatics & 0.247 & 0.184 & 0.209 & 0.289 & 0.930 \\
\hline & Biogenic VOC & 0.055 & 0.406 & 0.634 & 0.158 & 1.254 \\
\hline & C1-C2 aldehydes & 0.679 & 0.775 & 0.990 & 0.821 & 3.265 \\
\hline & Temperature-dependent Alkane & 0.899 & 0.569 & 0.623 & 0.908 & 2.998 \\
\hline & $\begin{array}{l}\text { Temperature-independent } \\
\text { Alkane }\end{array}$ & 0.095 & 0.069 & 0.082 & 0.109 & 0.355 \\
\hline & Sum & 2.341 & 2.258 & 2.801 & 2.667 & 10.07 \\
\hline
\end{tabular}




\section{References}

1. Technical Overview of Volatile Organic Compounds: https://www.epa.gov/indoor-airquality-iaq/technical-overview-volatile-organiccompounds\#3 (12 April 2017)

2. Volatile Organic Compounds in Your Home: https://www.health.state.mn.us/communities/enviro nment/air/toxins/voc.htm (15 June 2020)

3. Colborn, T., Kwiatkowski, C., Schultz, K., \& Bachran, M. (2011). Natural gas operations from a public health perspective. Human and ecological risk assessment: An International Journal, 17(5), 1039-1056; DOI: 10.1080/10807039.2011.605662

4. McKenzie, L. M., Witter, R. Z., Newman, L. S., \& Adgate, J. L. (2012). Human health risk assessment of air emissions from development of unconventional natural gas resources. Science of the Total Environment, 424, 79-87. DOI: 10.1016/j.scitotenv.2012.02.018

5. Eubanks, L. P. (2006). Chemistry in context: Applying chemistry to society. McGraw-Hill Education; pp 45

6. Goldstein, A. H., \& Galbally, I. E. (2007). Known and unexplored organic constituents in the earth's atmosphere. DOI: 10.1021/es072476p

7. Schnell, R. C., Oltmans, S. J., Neely, R. R., Endres, M. S., Molenar, J. V., \& White, A. B. (2009). Rapid photochemical production of ozone at high concentrations in a rural site during winter. Nature Geoscience, 2(2), 120-122. DOI:10.1038/ngeo415

8. EPA, U. (2000) National air pollutant emission trends 1900-1998. US Environmental Protection Agency.

9. Heminway, S. (1995). Profile of the Petroleum Refining Industry. EPA Office of Compliance Sector Notebook Project, US Environmental Protection Agency, Washington.

10. Swarthout, R. F., Russo, R. S., Zhou, Y., Miller, B. M., Mitchell, B., Horsman, E., ... \& Sive, B. C. (2015). Impact of Marcellus Shale natural gas development in southwest Pennsylvania on volatile organic compound emissions and regional air quality. Environmental science \& technology, 49(5), 3175-3184. DOI: $10.1021 / \mathrm{es} 504315 f$

11. Gilman, J. B., Lerner, B. M., Kuster, W. C., \& De Gouw, J. A. (2013). Source signature of volatile organic compounds from oil and natural gas operations in northeastern Colorado. Environmental science \& technology, 47(3), 1297-1305. DOI: 10.1021/es304119a

12. Jobson, B. T., Berkowitz, C. M., Kuster, W. C., Goldan, P. D., Williams, E. J., Fesenfeld, F. C., ... \& Riemer, D. (2004). Hydrocarbon source signatures in Houston, Texas: Influence of the petrochemical industry. Journal of Geophysical Research: Atmospheres, 109(D24). DOI: 10.1029/2004JD004887
13. Berkowitz, C. M., Jobson, T., Jiang, G., Spicer, C. W., \& Doskey, P. V. (2004). Chemical and meteorological characteristics associated with rapid increases of $\mathrm{O} 3$ in Houston, Texas. Journal of Geophysical Research: Atmospheres, 109(D10). DOI: 10.1029/2003JD004141

14. Kemball-Cook, S., Bar-Ilan, A., Grant, J., Parker, L., Jung, J., Santamaria, W., ... \& Yarwood, G. (2010). Ozone impacts of natural gas development in the Haynesville Shale. Environmental Science \& Technology, 44(24), 9357-9363. DOI: $10.1021 /$ es 1021137 